ARTICLE

Received 4 Dec 2015 | Accepted 6 Jun 2016 | Published 12 Jul 2016

DOI: $10.1057 /$ palcomms.2016.45

OPEN

\title{
Scientific advice in China: the changing role of the Chinese Academy of Sciences
}

\author{
Xiaoxuan $\mathrm{Li}^{1}$, Kejia Yang ${ }^{1}$ and Xiaoxi Xiao ${ }^{1}$
}

\begin{abstract}
This article explores the changing role of the Chinese Academy of Sciences (CAS) in the national scientific advisory system in China from an historical perspective, which has been divided into three periods. Period I (from 1949 to 1976) relates to the era during which, since its establishment, CAS assumed the role of the top-level scientific advisor to the Chinese government, and its dual role of "scientific advisory body" and "science and technology administrative organ" were especially evident during the formulation of "The TwelveYear National Long-term Outline for Science and Technology Development (1956-1967)". During period II (from 1977 to 2011) the function of providing scientific advice to the government was restored after the "Cultural Revolution", and CAS entered a new era of unprecedented prosperity and development. Finally, period III (from 2012 to present) includes Chinese President $\mathrm{Xi}_{\mathrm{i}}$ Jinping taking office, and the central government encouraging the development of science and technology think tanks, using third-party evaluation as an important measure and approach to promote the reform of the government management system. In summary, the new government attaches great importance to CAS, urging it, as a third-party organization, to fully play its role as a scientific advisor and further develop its capability and approaches to consulting, and improve its organizational structure. Given its prominent position in the Chinese scientific advisory system, the changing role of CAS also reflects the characteristics and changes in China's scientific advice throughout different periods. This article is published as part of a collection on scientific advice to governments.
\end{abstract}

\footnotetext{
${ }^{1}$ Institute of Policy and Management, Chinese Academy of Sciences, Beijing, China
} 


\section{Introduction}

S cientific advice has been a significant factor to be considered by national governments of various countries when making policies (Jasanoff, 2009; Arimoto and Sato, 2012; Australian and Government Department of Industry, 2012; Doubleday and Wilsdon, 2013). However, given the differences in political institutions and cultures across countries, the arrangements and methods for scientific advice are various, which have been widely discussed among scholars (Glynn et al., 2002; Wilsdon et al., 2014; OECD, 2015). National academies, as important resources for providing scientific advice to governments, have played a significant role in the national system, such as in the United States, the United Kingdom and other countries (Blair, 2006; Collins, 2011).

The Chinese Academy of Sciences (CAS), founded in 1949, is a primary scientific advisory institution in China (Cao, 2004). It comprises three major parts, which are a merit-based learned society, a comprehensive research and development network and a system of higher education. ${ }^{1}$ The merit-based part of Chinese Academy of Sciences is represented by the Academic Divisions of the Chinese Academy of Sciences (CASAD), with more than 700 members and 70 plus foreign members. The comprehensive research and development part of CAS consists of over 100 research institutions, with research areas covering almost the whole spectrum of the natural sciences. It includes 60,000 plus researchers and its funding for scientific research reached 45 billion RMB in 2014. Furthermore, there are more than 50,000 students studying in CAS. As a top research institution and national academy, CAS has held an important position in the Chinese advisory system since its establishment, and plays a significant role in providing scientific advice to government especially on those complicated and comprehensive issues involving science and technology.

Recently, the Chinese government has attached growing importance to the construction of think tanks, and particularly emphasizes the role of science and technology think tanks in government's advisory system. In 2013, Chinese President Xi Jinping urged CAS not only to play a leading role in scientific research but also build a high-caliber national science and technology think tank during his visit to CAS. Although there have been many reports about CAS's academic research and development strategies, demonstrating its role as a research institution, only a few introductions have been made to show its role as a scientific advisory body. Cao and Suttmeier (1999) introduce the policy roles of CAS members, and especially focus on the role of academicians, in providing recommendations for central government before 2000. However, this article explores the changing role of CAS, including both its academicians and research institutions, in Chinese scientific advisory system from an historical perspective, which can be divided into three periods. It is worth pointing out that the role of CAS in different periods reflects the characteristics and changes of the modes and approaches of Chinese scientific advice as for CAS's prominent position in the system.

\section{The highest-level scientific advisory body to government since its establishment}

Period I (1949-1976). After the People's Republic of China was founded, the Chinese government gathered almost all of the outstanding domestic scientists to establish CAS. In the early time of its establishment, apart from playing its role as a center of national scientific research, CAS performed as the administrative organ of national science and technology ${ }^{2}$ (Qian, 2010). As one of the government departments affiliated to the Government Administration Council of the Central People's Government (latter was named the State Council), CAS could make its own policies and decisions and also could coordinate all of the science and technology resources across the country to formulate and deliver policies.

As China's largest research body and also the important national research institution, CAS plays a significant role in providing scientific advice to support national science and technology development, which could be highlighted in the formulation of "The Twelve-Year National Long-term Outline for Science and Technology Development (1956-1967) (i.e., The Twelve-Year Plan (1956-1967))" with the dual role of "scientific advisory body" and "science and technology administrative organ".

At the early stage of 1950s, China entered the first stage of the planned economic system. To meet the needs of economic growth, it is necessary for China to have a long-term plan for the development of science and technology. In 1953, the CAS delegation of 26 scientists visited the Soviet Union to learn its experience on the development of science and technology. During this visit, it is one of the important concern of Chinese scientists that how to formulate the development plan of science and technology. It is after this visit that the Chinese scientists begin to consider the formation of academic divisions in CAS.

In 1955, the CASAD was founded as the leading body of the academia and the most authoritative academic senate in China. The formulation of the 15 years long-term development plan of science and technology was advocated at the inaugural meeting of the foundation of CASAD in June. The aim of this plan was to fully play the role of science and technology in the development of society and economy, and to meet the need of the national long-term development plan. In January 1956, En-lai Chou advocated the State Planning Committee and other related government departments working out the "The Twelve-Year National Long-term Outline for Science and Technology Development (1956-1967)" during the report on the question of intellectuals. Then the State Planning Committee of Science with 35 members was founded, led by Chen Yi, to be in charge of ${ }^{3}$ the working out of "The Twelve-Year Plan" (Wu, 1994).

"The Twelve-Year Plan" is the first long-term plan to encourage the development of science and technology in New China. This plan set out the general objectives of the national science and technology development, putting forward 57 programs and 600 plus research subjects, involving important fields and crucial issues of scientific and technological development, such as semiconductor technology, computer technology, automation technology, radio technology, nuclear technology and jet technology (Li, 1991; Hu, 2006; Yang and Zhang, 2007). Thanks to this plan, a large number of research institutions were established, and the number of research staff also had a substantial increase, which laid the foundation for the establishment of New China's science and technology system promoting the emergence and development of a series of new industries and sectors of industries in agriculture and national defense. This plan was formulated through the support of entire nation, and the CASAD played a leading role to coordinate more than 600 scientists and engineers under the leadership of the State Planning Committee of Science(Li, 1999).

There are two major stages to work out this plan. Stage 1: Drafts of departmental plan were submitted by CAS, universities, industries and national defense departments respectively at the end of February 1956. Stage 2: Including the academicians in the Division of Mathematics \& Physics \& Chemistry, the Division of Life Sciences \& Earth Sciences and the Division of Technological Sciences in CAS, the CASAD organized more than 600 scientists and engineers, working in a general group and several special groups, to collect, integrate and review the separated draft plans 
into a synthesis report. In August 1956, The Twelve-Year Plan was completed through the underpinning efforts of CAS.

As the administrative function of CAS had seriously affected its construction as national scientific research center, CAS had no longer undertaken the function of national science and technology administration since 1950s, which was transferred to the State Science and Technology Commission ${ }^{4}$ founded in 1958, and CAS became one of the highest academic institutions under the leadership of the State Council. At the same time, the advisory function of CAS was also partly replaced by the State Science and Technology Commission, such as the role of working out the long-term plan for the development of national science and technology.

Apart from organizing and coordinating the scientists and engineers across the country to work out The Twelve-Year Plan, CAS also provided some other important scientific advices as the top scientific advisory institution until the occurrence of Cultural Revolution in 1966(Wang, 2015). In the 10-year-long turbulence, the scientific advisory work of CAS was seriously affected ${ }^{5}$ and the General Assembly of the CAS Members was suspended for 20 years after the Third Assembly held in 1960.

During this period (1949-1976), science was easily affected by the politics especially in the context of the planned economic system. Scientific advices were often used as explanations and descriptions of the political slogans rather than the objective and sound evidences to support decisions. As the top institution, CAS played a significant role as the highest scientific advisory body to support the strategy development of the national science and technology especially at the birth of New China, where a thousand things wait to be done. However, due to the incomplete scientific advisory system, CAS was easily affected by politics, especially during the Cultural Revolution, the survival of scientists were seen as problems, let alone to guarantee the freedom of providing scientific opinions (Cao and Suttmeier, 1999).

\section{The restoration and prosperity of CAS's function as a scientific advisor}

Period II (1977-2011). After Cultural Revolution, the government increasingly emphasizes the importance of science and technology in serving economic growth and social progress, advocating the strategic concept of "science and technology are the primary productive force", "Economic development must rely on science and technology, and the latter should be oriented toward the former", "Science and Education for a Prosperous China"(Li et al., 2015). Meanwhile, the Chinese government vigorously promoted the scientific and democratic construction of the government's decision making system (Wang, 2008; Hou, 2009), thus giving an extended period of scientific advice prosperity in China(Cheng, 2005). During this period, scientific advice not only played an important role in policy-making for development of science and technology, but also actively exerted influences on policy-making on other science and technology issues related to social and economic growth(Cao, 2004; Zheng et al., 2013).

In January 1979, after the national science conference was held, the activities of CASAD was restored, and 2 years later the Fourth General Assembly of CAS Members was convened, ${ }^{6}$ now the Assembly convenes regularly every 2 years(Wei, 2006). During this booming period, both Academic Divisions and research institutions of CAS leveraged its advantages and strengthened the cooperative communication with other departments, so as to give a full play to its role as a scientific advisor to government's decision making through a variety of channels. As the highest national advisory body on science and technology and a traditional merit-based academic society, the CASAD provides advice mainly through academicians. CAS's research institutions have large research resources to support scientific advisory work, by taking advantage of different strengths of research institutes, such as organizing interdisciplinary specialists and scholars across institutes.

Providing scientific advices to government mainly through CAS academicians. In 1984, the State Council, China's cabinet, officially stated that the CASAD is the highest national advisory body on science and technology. Since then, the CASAD had gradually attached more attention on providing scientific advice through CAS academicians rather than playing the role of an academic senate as in its initial stage (Wang, 2015). To improve the advisory role of CASAD, the government allocated funding to support academicians to conduct advisory activities, and more internal and external meetings were held to discuss research priorities and policy issues. For example, the General Assembly of the Members of CAS and CAE (Chinese Academy of Engineering) is held biennially, and top leaders of the central government attend the meetings, discussing the important subjects of scientific research in the next few years and how the development of science could fully serve national needs.

The consulting activities of CAS academicians mainly focus on the important fields of national long-term interests, for instance, the long-term science development plans and large-scale programs, and crucial and complicated issues of economy growth. Numerous scientific suggestions provided by academicians have been adopted by the government, such as the establishment of the National Natural Science Foundation of China in 1986, the setting up of 863 program in 1986, and the founding of CAE in 1994(Sheng and Han, 1999). Besides, to fully play the role as a scientific advisory body, CASAD strengthens the cooperation with government departments, universities and other research institutions. Some large-scale projects, like SouthNorth Water Transfer Project, Qinghai-Tibet Railway Project, are all based on the evidence and scientific research from the joint efforts of academicians in CAS and CAE.

There are many channels for CAS academicians to support government decision-making. For instance, through research projects commissioned by government departments, research reports were provided initiatively to support the government, and ideas of its members could also be delivered to the top government leaders directly through special channels. To guarantee that CASAD could conduct its research projects independently, stable funding was allocated for its Members to focus on research areas where they are interested in. There are mainly two types of working patterns, one is to rely on the joint efforts of academicians from different divisions and disciplines to address more comprehensive issues, and the other is to assign individual division to deal with specific issues. The study process of $\mathrm{CASAD}^{7}$ is demonstrated in Fig. 1.

To guarantee the high quality of the advisory work, the Consultation and Evaluation Committee and the Committee of each Academic Division invite experts from CAS and other external experts to review the report independently. After the review, the report ${ }^{8}$ will be revised for several times. For those advisory work conducted initiatively by CAS, the advisory reports will be provided directly to related government departments. Also, the reports are sometimes delivered and released to the public.

One typical case of providing scientific advice initiatively is the formulation of "Science \& Technology in China: A Roadmap to 2050", which was released in 2009. To address issues, such as energy, environmental and large population problems in China, CAS realized that further strategic priorities for science and technology development should be worked out with a long-term 


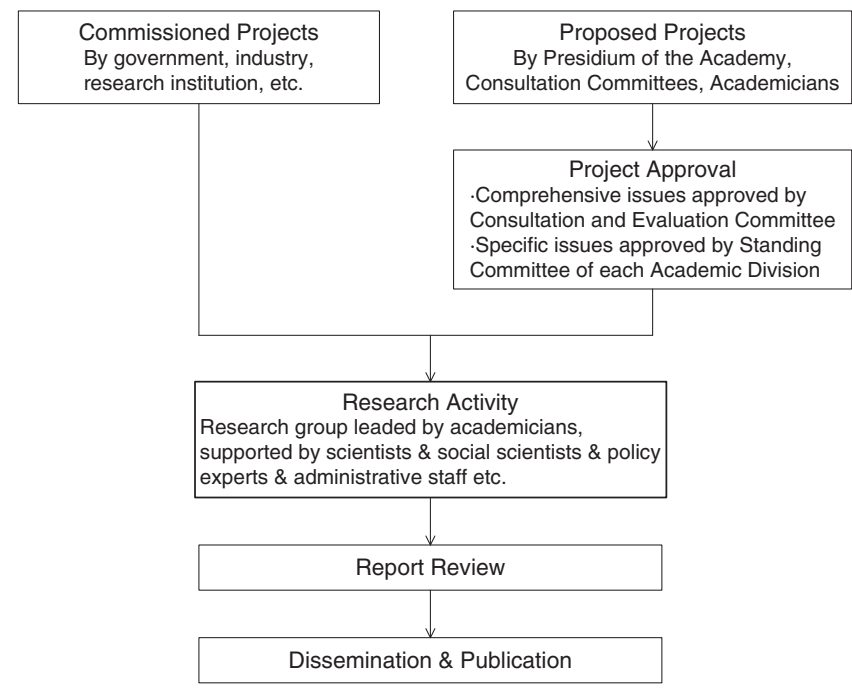

Figure 1 | Study process of CASAD.

view. In July 2007, the former CAS President Lu Yongxiang advocated CAS to lay out a science and technology roadmap for the next 20-30 years. According to the Executive Management Committee of CAS, the strategic research on science and technology roadmap for future development should be conducted to orchestrate the needs of both the nation and society, and target at three objectives: the growth of economy and national competiveness, the development of social harmony, and the sustainability between man and nature (Lu, 2010).

Relevant workshops were organized with the participation of scientists both within CAS and outside to discuss the research priorities and objectives. More than 300 experts, including 60 academicians and other scientific and technological experts, management experts and intelligence experts from around 80 research institutes of CAS, were involved in the process of drawing this roadmap. The final work includes a general report and 17 special ones on sub-fields such as energy, population health, mineral resources, space and ocean, information, materials, ecology and environment (CAS, 2009). The general report identifies crucial science and technology areas in the following 50 years in China, figures out the characteristics of these areas and objectives for their progress, and also sets out research agendas to achieve the progress. It provides sound evidence for government to make strategic decisions for development of science and technology in China. After the reports finished, they were delivered to both central government and local government and also were released to the public.

Apart from the above two modes presented in Fig. 1, there are special channels for academicians to present their ideas directly to the top national leaders. For instance, in May 1981, during the Fourth General Assembly of the CAS Members, 89 academicians jointly signed a letter, calling on the government to support basic research across the country. The suggestion of setting up the Science Foundation of CAS, which was later restructured as the National Natural Science Foundation of China, was seriously considered and adopted by the central government. During the late 1980s and the early 1990s, the tide of science and technology system reform waves across the nation, numerous scientific advisory reports on crucial issues were provided by academicians through this special channel to affect government's decisions on science and technology development, such as, the setting up of "National High Technology Research and Development Program (863 Program)" to follow the international advanced technology
( $\mathrm{Ru}$ and $\mathrm{Su}, 2010$ ), and some of them were completely adopted by central government.

Providing scientific advice to government mainly through the platform formed by research institutes. There are three major channels for research institutes to play the role as scientific advisory bodies. The first one is to jointly provide scientific advice on comprehensive issues. The second one is to conduct research works individually on specific issues. The third one is through the professional knowledge provided by prominent scholars as experts in scientific advisers group organized by government departments. In order to motivate research institutes to provide scientific advice to government, the number and impact of advisory reports is also used as an indicator to evaluate the institute's performance. ${ }^{9}$

The mode of providing scientific advice through research institutes can be seen from the draft of "National Major Function Oriented Zoning Plan". To remedy the situation that economy growth based on the excessive consumption of resources, the central government realized that it is necessary to develop a scientific and rational overall planning of regional development in China(Wu, 2015). Before National Development and Reform Commission (NDRC) commissioned CAS to conduct research into this issue, CAS had been working on it from 2003(Fan, 2013). The process that CAS plays its role as scientific advisory body to affect the government could be divided into three stages (Zhang, 2010).

Stage 1, expert groups were set up in CAS, which is led by three academicians and supported by research groups headed by Fan Jie from the Institute of Geographic Sciences and Natural Resources Research (IGSNRR), CAS. Fan Jie was also appointed as the Chief Scientist of the working group to fully in charge of the work. ${ }^{10}$ After several communications with NDRC and scientific studies were conducted, the working group finally finished the scientific advisory report, dividing the national territory into five categories according to the area's level of economic development and resource \& environmental bearing capability. The concept in the report was adopted by the government and accordingly the original five categories were replaced by "four main functional areas"(Zhang, 2010). The four areas are: prioritized development area, optimized development area, constrained development area and forbidden development area. Stage 2, based on the advisory report, NDRC commissioned the research group which was leaded by Fan Jie to work out how to develop the constrained development area. The method that put forward by the group was completely adopted in China's "11th Five-Year Development Guidelines (2006-2010)", which was guideline for China's next five years development of economy and society. Stage 3, the research group directly participated in formulating the "National Major Function Oriented Zoning Plan" as in charge of the first part to provide assessment criteria and methods of National Major Function Oriented Zoning.

\section{Standardization and institutionalization of "science and technology think tanks"}

Period III (2012 - present). Since the 18th National Congress of the Communist Party of China, the new government Xi Jinping has officially declared the concept of governance to push the reform of government management system, encouraging involvement of various non-government forces in governance. To improve the capability of consulting system, the central government extremely advocates the construction of "science and technology think tanks", identifying 25 high-quality think tanks ${ }^{11}$ as pilot units in December, 2015. CAS is one of the 25 highquality think tanks. 
The central government states that it should decentralize its administrative authority and invite third-party organizations to evaluate the effect of its policies and measures. We assume that the third-party evaluation is one of the advisory activities, which is quite distinct due to its clear objectives and specific logic models. The third-party evaluation of government performance has been a critical measure taken by the central government to promote the reform of government management system (Xie, 2014), and the Premier of China's State Council, Li Keqiang claimed that this measure should be a regular mechanism to supervise the government to ensure that their polices and measures achieve the desired results. ${ }^{12}$ Currently, the thirdparty evaluation reports are supposed to be presented to the State Council and also should be presented in the State Council executive meeting, which was hosted by Li Keqiang. Problems presented in the report should be solved by the heads of related government departments in a certain period of time.

In this context, the central government raised new expectations and requirements of CAS as the role of advisory body. During his visit to CAS in July 2013, Chinese President Xi Jinping urged the academy to take the lead in setting up a highlevel national science and technology think tank. In response to the demands of the government, CAS has actively launched the government's third-party evaluation projects on the one hand, and promoted the standardization and institutionalization of its function of providing scientific advice to improve its capability on the other hand.

A number of projects were commissioned from CAS since September 2013 when the State Council started the third-party evaluation activities to supervise government performance. Some of them were commissioned by the State Council, such as the assessment of "Drinking Water Safety in Rural Area Program" and "National Poverty Reduction Program (jing zhun fu pin)" (Center, 2014; Wang and Li, 2015). Some were commissioned by ministries and commissions directly under the State Council, for instance, "Consultation and Deliberation of Whether China Should Participate in Square Kilometer Array (SKA) Program" was commissioned by Ministry of Science and Technology (MOST) and undertaken by the CASAD, "The Performance Assessment of China Agricultural Research System" project was commissioned by the Ministry of Finance and the Ministry of Agriculture to the Research Center of the Third-Party Evaluation of CAS.

Take the assessment of "Drinking Water Safety in Rural Area Program" as an example. In 2014, the State Council commissioned the IGSNRR of CAS to assess the performance of "Drinking Water Safety in Rural Area Program", which was conducted by the Ministry of Water Resources in the period of the "National Twelfth Five-year Plan(2011-2015)". CAS realized that it was a complicated project that required a large amount of human and scientific resources, and as such it authorized the CAS's Bureau of Development and Planning to be fully in charge of the project under the leadership of the president of CAS, Bai Chunli. On the basis of dozens of field researches, workshops and interviews with local farmers, experts from the IGSNRR and other CAS institutes assessed the performance of the program with the focus on the following aspects: the selection and protection of rural area's water sources, the management and maintenance of operation during and after project construction, water quality and quantity, the convenience and satisfaction of water-users and so on.

In contrast to the previous performance assessments of government department's programs, which were normally organized by the government itself with participation of related experts, this assessment project was conducted by an independent third party, CAS, which could perform with a relatively objective perspective to assess the performance of the government, to identify problems and put forward solutions through a large number of researches and investigations to support future implementation of the program.

To ensure that CAS could implement the third-party evaluation activities effectively and efficiently, efforts are made continually to explore the appropriate management systems and also to improve evaluation methods and approaches. Take "Consultation and Deliberation of Whether China Should Participate in SKA Program" for example, it was conducted by a special organization, the Research Center of the Third-Party Evaluation of CAS, rather than through the traditional consultation mechanism that working out the report after several communications and discussions with academicians, the new working pattern of "working group cooperating with expert group" was adopted in CAS to guarantee the high quality of advisory report.

The SKA is a large multi radio telescope project aimed to answer fundamental questions about the origin and evolution of the Universe, which is built in Australia and South Africa. It would have a total collecting area of approximately $1 \mathrm{~km}^{2}$ and be able to survey the sky more than 10,000 times faster than ever before once built. However, it is a large-scale and comprehensive project which requires a large amount of money and scientific resources with the collaboration of multi-nations (https://en. wikipedia.org/wiki/Square_Kilometre_Array). It will require high performance and reliable research facilities, such as, high performance central computing engines and low cost broadband antenna, and these techniques will involve many research areas like the astronomy, radio, information science, mechanical engineering, computational mathematics and systems science and so on (http://www.most.gov.cn/mostinfo/xinxifenlei/fgzc/ gfxwj/gfxwj2015/201512/t20151210_122801.htm).

In March 2015, MOST commissioned CASAD to take an assessment on whether China should participate in SKA program considering the ability and capacity of Chinese scientific resources. To guarantee the high quality of the advisory work, it was conducted by a special organization, the Research Center of the Third-Party Evaluation of CAS, one of the five supporting centers to support academicians to conduct advisory activities of the Institutes of Science and Development of CAS (CASISD), which was founded as an integration platform for advisory activities in CAS. During the advisory process, a new working mechanism was designed to maintain balance and objectivity throughout the work. After several consultations with related experts, an expert group, with 17 prestigious specialists from different perspectives and research areas, was set up, 15 of them are academicians from CAS and one from CAE. The research areas of the experts covered several subjects, for example, Astronomy, Physics, Electronics, Information, Earth Science, and also one expert is specialized in science and technology assessment. The leader of the expert group was chosen for his relatively neutral identity and full of experience.

To guarantee the high quality and the efficiency of the advisory work, a working group was also set up to support the scientific activities, such as collection of data and related materials, negotiation with experts, organization of workshops and seminars, drafting reports and other supporting works. The working group is comprised of staff from National Astronomical Observatories of CAS, National Science Library of CAS (NSLC), Bureau of Academic Divisions of CAS, Research Center of the Third-Party Evaluation of CAS and so forth. This new working pattern with the support of working group could avoid the shortcomings of the low quality caused by the lack of time of experts. The report was finished by the working group with the advisory and supporting from the experts, and was revised for 


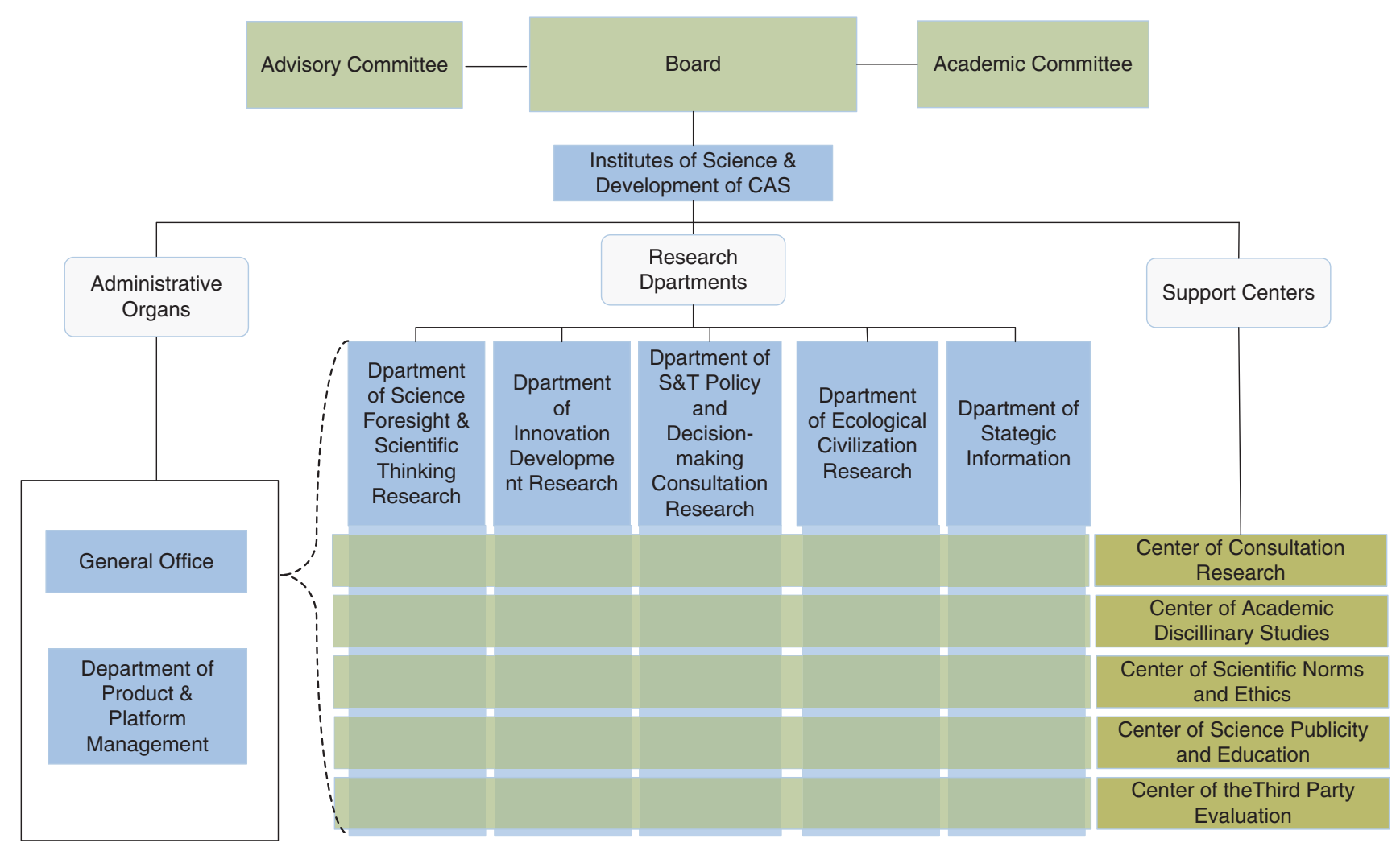

Figure 2 | Organizational structure of CASISD.

Source: internal report for 4th meeting of Presidency Office provided by Office of the CAS committee for Science Think-Tank Development.

several times through communications with experts individually by email and face to face to reach a clear and balanced opinion. The final version of the report was presented to the government with the statement of opinions and evidence.

The new working mechanism of "expert group" cooperating with "working group" was designed by CAS to fully collect experts' opinions from different perspectives. This working pattern can make the best use of the time of experts and present the report in the language that can be understood by policymakers, as the "working group" includes policy experts not just technology experts. Also, the final report presented clear opinions with sound evidence rather than just collections of different views, and that could be used directly by policymakers. This working mechanism of advisory is one of the new explorations of CAS to reform its advisory system.

As one of the critical measures taken by the central government to promote the reform of government management system, the third-party evaluation plays an important role to push the construction of a sound supervision mechanism of government, which requires the third party must be objective and scientific. From the perspective of objective, it does not mean that third party is absolutely disinterested organization, but to be objective with fully consideration of views from all the stakeholders. As the third party, CAS can play a relatively objective role in assessment of the performance of "Drinking Water Safety in Rural Area Program", whereas, it is one of the stakeholders in the "Consultation and Deliberation of Whether China Should Participate in SKA Program". But the latter program has been conducted successfully by CAS considering the balanced views of all related scientists from different perspectives to improve the objectivity and scientificity of the report.
In June 2015, based on the Institute of Policy and Management, Chinese Academy of Sciences, CASISD ${ }^{13}$ was founded as a corporate body, with other research staff from IGSNRR, NSLC and the Institute for the History of Natural Sciences of CAS. CASISD is constructed as a research and supporting institute to support and assist academicians in providing strategic consultations for central government and also is constructed as a research and advisory platform to conduct research projects by integrating all the research resources of CAS. The relationship between CASISD and CASAD is similar as the relationship between NRC and National Academies, and Science Policy Center and the Royal Society. However, there are some differences, as CASISD could also integrate research forces from other research institutes across CAS. CASISD's organizational structure could be demonstrated in Fig. 2.

The chair of the board of CASISD is Bai Chunli, the president of CAS. There are two committees of CASISD, one is the Advisory Committee, which is made up of external experts and the other is the Academic Committee, the CAS Committee for Science Think-Tank Development, which is made up of internal experts of CAS. There are mainly five research departments of CASISD focusing on five different research areas based on the research institutes and research centers of CAS, orienting by their own research tasks and problems in their research frontier. The five departments are: Department of Science and Foresight and Scientific Thinking Research, Department of Innovation Development Research, Department of Science and Technology Policy and Decision-Making Consultation Research, Department of Ecological Civilization Research, and Department of Strategic Information. There are mainly five research centers to support academicians to carry out their advisory activities, disciplinary studies, scientific norms and ethics studies, science publicity, and third-party evaluation activities respectively. Apart from 
supporting the academicians to carry out the third-party evaluations, the Research Center of the Third-Party Evaluation also support CAS to carry out research institutes' performance evaluation. CASISD also coordinates with University of CAS to push the integration of science and education. There is also a communication and data sharing platform to release the research productions of CASISD to the public.

As one of the 25 pilot units of the construction of high-quality think tanks in China, the CASISD is still on its way to explore and construct a sound mechanism in Chinese situation considering the experience of US NRC(National Research Council) and other advisory bodies in the world, and there are various issues, such as how to guarantee its independency and high quality of advisory report in China's current political and economic context, should be tackled before it reach the nation's expectation of being a highcaliber national science and technology think tank. There are many challenges for CAS to overcome compared with NRC and Royal Society, like how to guarantee independence of CAS with an extensive network of research institutes as "in house" resources.

\section{Conclusion}

We can draw some conclusions from what we have discussed in regard to the changing role of CAS in the Chinese scientific advisory system by means of an historical review. As the most prestigious academic research institute and a national academy, CAS has been playing a significant role in providing advice for government since its establishment. However, we divide it into three periods according to the different roles it played.

Period I (1949-1976): CAS was assigned as the top-level scientific advisor to Chinese government since its establishment, and its dual role of "scientific advisory body" and "science and technology administrative organ" especially evident through the process of making "The Twelve-Year National Long-term Outline for Science and Technology Development (1956-1967)”.

Period II (1977-2011): after Cultural Revolution, scientific advice had never been in greater demand to tackle problems confronted in China's economic and social development and Chinese government also vigorously promoted the scientific and democratic construction of government's decision-making system, thus giving an extended period of scientific advice prosperity in CAS. During this period, a structured institutional system was formalized both in CASAD and research institutes of CAS and a large amount of high quality scientific advisory reports were produced.

Period III (2012 to present): with the promotion of reform in government management system, the new government extremely advocates the construction of "science and technology think tanks", stating that the central government should decentralize its administrative authority and invite third-party organization to evaluate government performance. Under this background, the construction of think tank ushered in a new era of standardized and institutionalized system. CAS, as the third-party organization, actively explores a new mode to give full play to its unique advantages, integrating research resources from the Academic Divisions and Research Institutes, to further develop its consulting approaches and improve its consulting capability and organizational structure.

Considering the prominence of CAS in Chinese scientific advisory system, the changing role of CAS reflects, to some extent, the characteristics of China's scientific advice and its development. Two points could be drawn out.

The first point is that the Chinese government increasingly pays more attention to the construction of science and technology think tanks and the structure of the scientific advisory system has greatly improved. Since the 16th National Congress of the
Communist Party of China, the government has been repeatedly emphasizing that policy-making mechanisms should be reformed and improved so as to ensure policy-making is more scientific and democratic. After the 1980s, various advisory bodies sprang up to conduct research and explorations on technological, industrial and major strategic policies so as to support government policy-making ( $\mathrm{Li}$ et al., 2015). In recent years, with the advocating of the concept of governance to push the reform of government management system, the central government attached great importance on the third-party organization to push the construction of government's supervision mechanism. However, there are still challenges to keep the balance of objectivity and influence of think tanks in China, and the influence power of non-governmental organization on government decision-making is still much weaker than those traditional think tanks. Moreover, there is much more to do to improve the objectivity and independence of the third-party organization in China. It is necessary for the central government and the politicians to understand the importance and respect the independence of third-party organizations to play their due role. Also, third-party organizations, such as research institutions, universities, associations and societies, and NGOs, should strictly control the process of their study to maintain the high quality of their research reports.

The second point is that even though the Chinese government has been promoting the development of scientificity of decision making since $1980 \mathrm{~s}$, there are still numerous problems to be addressed, like the lack of laws to guarantee the independence of think tanks. Other problems like how to adjust organizational structure and improve evaluation approach to work efficiently in Chinese situation, how to guide and motivate scientists and engineers and other experts to engage in scientific advice activity, are still should be tackled for think tanks to improve the quality of their scientific advisory activities. Currently most CAS scientists prefer to do more research experiments and publish more research papers, rather than involving themselves in advisory activities and providing advisory reports. It is encouraging that CAS is exploring solutions to all these problems and advancing itself to the national high-level science and technology think tank as required by Chinese President Xi Jinping.

\section{Notes}

1 Brief introduction to CAS, http://english.cas.cn/about_us/introduction/201501/ t20150114 135284.shtml.

2 There was no MOST (Ministry of Science and Technology of the People's Republic of China) or other regulatory authority on science and technology in China at that time, so CAS was performed as an administrative organ to be in charge of the national development of science and technology and the management of scientific resources. However, the role of CAS as an administrative organ was not clear at that time.

3 The State Planning Committee of Science was founded to take full charge of the formulating of the Twelve-Year Plan. However, given its small group members, individual area plan designing was undertaken by individual groups in different areas For example, the State Technology Commission was in charge of the plan designing in industries and transportations, CAS was in charge of the development of basic sciences, Department of Agriculture and Department of Health was in charge of plan designing in agricultures and medical sciences respectively.

4 The State Technology Commission was founded in 1956 to fully in charge of working out the 5 years and long-term plan for technology development; The State Planning Committee of Science was founded later in the same year to be in charge of working out the "The Twelve-Year National Long-term Outline for Science and Technology Development (1956-1967)"; then in 1958, the two commissions were merged into one, named the State Science and Technology Commission, which was renamed as MOST in1998 after the reform of the scientific management system in China.

5 The activities of the Academic Divisions came to a complete halt for more than 10 years.

6 Review of the history of General Assembly of the members of the CAS, http://www. cas.cn/zt/hyzt/zgkxydswcysdh/ljysdhhg/. 
7 Regulations on the Management of Consulting Projects of the Chinese Academy of Sciences, http://www.casad.ac.cn/doc/14870.html.

8 CAS generally provides recommendations on policies and sometimes it also offers policy options.

9 Advisory report was one of the CAS institute performance indicators at that time. Other indicators include publications, patents, projects, talents and rewards and so on.

10 Zhang Fuxing. CAS provided scientific advice for the formulation of "National Main Functional Area Plan". China Science Daily, 2010-7-6.http://www.cas.cn/xw/cmsm/ 201007/t20100706_2893082.shtml.

1125 high-quality think tanks as the pilot units, http://www.js.xinhuanet.com/2015-12/ 04/c_1117358781.htm[2016-3-20].

12 Wang ziyue. Reports of third-party evaluation were presented to State Council: it was declared that the third-party evaluation of government performance should be a regular mechanism held every year. Yicai Daily, http://finance.sina.com.cn/china/ 20140901/021720173303.shtml[2014-9-1].

13 Brief introduction of CASISD, http://english.casisd.cn/about/introduction/index. html.

\section{References}

Arimoto T and Sato Y (2012) Rebuilding public trust in science for policy-making. Science; 337 (6099): 1176-1177.

Australian \& Government Department of Industry, I., Science, Research and Tertiary Education. (2012) APS200 Project: The Place of Science in Policy Development in the Public Service. Canberra.

Blair P (2006) Scientific advice for policy in the United States: Lessons from the National Academies and the former Congressional Office of Technology Assessment. Berlin, Germany.

Cao C (2004) China's Scientific Elite. Routledge: London.

Cao C and Suttmeier RP (1999) China's "brain bank": Leadership and Elitism in Chinese science and engineering. Asian Survey; 39 (3): 525-559.

CAS, B. O. B. S. (2009) Excerpts of the report of "science \& technology in China: A roadmap to 2050. Frontier Science; 3(11): 4-19.

Center, I. P. O. M. (2014) Using third-party evaluation approach to supervise state council for the first time. Information for Deciders Magazine; (35): 26-27.

Cheng S (2005) Vigorously promoting the development of soft science to advance the scientific and democratic construction of decision making. China Soft Science; (4): 1-6.

Collins P (2011) Quality control in scientific policy advice: The experience of the royal society. In: Lentsch J and Weingart P (eds). The Politics of Scientific Advice: Institutional Design for Quality Assurance. Cambridge University Press: Cambridge, UK, pp 334-341.

Doubleday R and Wilsdon J (eds) (2013) Future directions for scientific advice in Whitehall. Alliance for Useful Evidence \& Cambridge Centre for Science and Policy: London.

Fan J (2013) The strategy of major function oriented zoning and the optimization of territorial development patterns. Bulletin of the Chinese Academy of Sciences; 28(2): 54-67.

Glynn S, Cunningham P and Flanagan K (2002) Typifying Scientific Advisory Structures and Scientific Advice Production Methodologies (TSAS). Draft Final Report, PREST, University of Manchester: UK.

Hou J (2009) Development history and its future improvement approaches of CPC's scientific and democratic decision-making system. Weishi; (3): 23-25.

$\mathrm{Hu} \mathrm{W}$ (2006) The 12-year long-term science and technology development plan: Planning, effect and some enlightenments. Bulletin of Chinese Academy of Sciences; (3): 207-212.

Jasanoff S (2009) The Fifth Branch: Science Advisers as Policymakers. Harvard University Press: Cambridge, MA.

Li A (1999) A milestone in the history of New China's science and technology development-The Twelve-Year National Long-term Outline for Science and Technology Development (1956-1967). Science News; 30(28):

Li H (1991) Historical review of "the twelve-year national long-term outline for science and technology development (1956-1967)". Truth Seeking; (4): 20-21.

Li X, Yang K, Zhang X, Liu X and Liu Z (2015) A Comparative Study on How Todevelop an Evidencebased Approach to Policy-Making. Science Press: Beijing, China.
Lu Y (Editor in Chief) (2010) Science \& Technology in China: A roadmap to 2050; Strategic General Report of the Chinese Academy of Sciences. Science Press: Beijing, China.

OECD. (2015) Scientific Advice for Policy Making: The Role and Responsibility of Expert Bodies and Individual Scientists. OECD Science, Technology and Industry Policy Papers, No. 21, OECD Publishing: Paris, http://dx.doi.org/10. 1787/5js3311jcpwb-en.

Qian B (2010) Formation of science and technology management system in the early years of new China. Contemporary China History Studies; 17(3): 44-51 $+125-126$.

$\mathrm{Ru} \mathrm{P}$ and Su J (2010) Research on the influence of scientists in science and technology decision making-Taking 863 program as example. China Soft Science; (10): 86-92.

Sheng H and Han C (1999) Academic Divisions of Chinese Academy of Sciences: National Science Think Tank, National Highest Scientific Advisory Body. Science News; (32): 22-23.

Wang J (2008) Research review of ten years history of government's scientific and democratic decision making system-From the 15th national congress to the 17th national congress. Journal of Xinyang Normal University (Philosophy and Social Science Edition); (4): 21-24.

Wang J and Li Y (2015) The third-party evaluation report of supervision of state council's policies and measures conducted by geographers. Acta Geographica Sinica; (10): 1694-1695.

Wang Y (2015) Reflections on the history of the CASAD at its 60 anniversary. Bulletin of Chinese Academy of Sciences; 30 (3): 414-420.

Wei L (2006) Research on the evolution of function and mission of Academic Divisions of CAS. Management and Review of Social Sciences; (1): 35-46.

Wilsdon J, Allen K and Paulavets K (2014) Science Advice to Governments. A briefing paper for the Auckland conference, 28-29 August. Auckland.

Wu F (2015) Planning for Growth: Urban and Regional Planning in China. Routledge: New York, pp 119-142.

Wu H (1994) The Fifty Years History of Science and Technology in China from 1940 to 1990 (Ke ji zhan xian wu shi nian). Scientific and Technical Documentation Press: Beijing, China, pp 159-167.

Xie W (2014) Government decentralization scoring by third-party evaluation report. China Economic Weekly; (43): 62-65.

Yang W and Zhang M (2007) Making and implementation of the first plan of scientific and technological development in new China and the histrocial experience. CPC History Studies; (6): 42-49.

Zhang F (2010) CAS provided scientific advice for the formulation of "National Main Functional Area Plan". China Science Daily. http://www.cas.cn/xw/ cmsm/201007/t20100706_2893082.shtml

Zheng C, Yang D and Jingru L (2013) An analysis of the model of scien-tech organisations' participation in decision making and consultancy. First Resource; (1): 131-147.

\section{Data availability}

Data sharing not applicable to this article as no datasets were generated or analysed during the current study.

\section{Additional information}

Competing interests: The authors declare no competing financial interests.

Reprints and permission information is available at http://www.palgrave-journals.com/ pal/authors/rights_and_permissions.html

How to cite this article: Li X, Yang K and Xiao X (2016) Scientific advice in China: the changing role of the Chinese Academy of Sciences. Palgrave Communications. 2:16045 doi: $10.1057 /$ palcomms.2016.45.

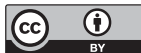

This work is licensed under a Creative Commons Attribution 4.0 International License. The images or other third party material in this article are included in the article's Creative Commons license, unless indicated otherwise in the credit line; if the material is not included under the Creative Commons license, users will need to obtain permission from the license holder to reproduce the material. To view a copy of this license, visit http://creativecommons.org/licenses/by/4.0/ 